\title{
Regulación en legislación cooperativa vasca de la contribución para la educación y promoción cooperativa y otros fines de interés público y cuestiones que plantea
}

(Regulation in Basque cooperative legislation of the contribution to cooperative education and promotion and other purposes of public interest and issues raised)

Iñigo Nagore Aparicio ${ }^{1}$

Universidad del País Vasco (España)

Sumario: I. Regulación vasca vigente. I.1 Regulación básica. I.2. Regulación en caso de modificación estructural, y disolución y liquidación. I.3. Comentario general. II. Evolución de la legislación vasca. II.1. La ley de 1982. II.2. La ley de 1993. II.3. El reglamento de 2005. II.4. La modificación de 2008 de la ley de 1993. III. Regulación estatal. IV. Principios cooperativos que lo sustentan. V. Cuestiones que plantea.

Summary: I. Current Basque regulation. I.1 Basic regulation. I.2. Regulation in case of structural modification, and dissolution and liquidation. I.3. General comment. II. Evolution of Basque legislation. II.1. The 1982 law. II.2. The 1993 law. II.3. The 2005 regulation. II.4. The 2008 amendment to the 1993 law. III. State regulation. IV. Cooperative principles that sustain it. V. Questions raised.

Resumen: El artículo analiza la evolución del Fondo de Educación y Promoción en la legislación cooperativa vasca y la actual regulación estatal. Tras recordar los principios inspiradores de la Alianza Cooperativa Internacional plantea aquellos puntos de la regulación que a su juicio son mejorables.

Palabras clave: Cooperativas, Fondo de Educación y Promoción, Contribución para la educación y promoción cooperativa y otros fines de interés social, dotación, destino, plazos, canalización, inembargabilidad, control.

Abstract: The article discusses the evolution of the Education and Promotion Fund in Basque cooperative legislation and current state regulation. Re-

1 Doctor en Derecho. Abogado-economista. Profesor ac. Agregado de UPV/EHU (Unibasq). Email: inagore@nagore.eu 
calling the inspiring principles of the International Cooperative Alliance it raises those points of regulation that it believes could be improved.

Keywords: Cooperatives, Education and Promotion Fund, Contribution to cooperative education and promotion and other purposes of social interest, endowment, destination, deadlines, channeling, immunity from seizure, control. 


\section{Regulación vasca vigente}

LEY 11/2019, de 20 de diciembre, de Cooperativas de Euskadi, de 30 de diciembre de 2019 (BOPV 247)

\section{I.1. Regulación básica. Arts. 70 (números 1 a 3) y 72}

\section{«Artículo 70.-Distribución de excedentes.}

1.-Los excedentes netos, una vez deducidas las cantidades que se destinen a compensar pérdidas de ejercicios anteriores y a atender los impuestos exigibles, constituirán los excedentes disponibles.

2.-Anualmente, de los excedentes disponibles se destinará:

a) Al Fondo de Reserva Obligatorio y a la contribución para la educación y promoción cooperativa y otros fines de interés público una cuantía global del treinta por ciento, al menos, destinándose, como mínimo, un diez por ciento a la contribución para la educación y promoción cooperativa y otros fines de interés público y un veinte por ciento al Fondo de Reserva Obligatorio.

b) El resto estará a disposición de la asamblea general, que podrá distribuirlo en la forma siguiente: retorno a las personas socias; dotación a fondos de reserva voluntarios, con el carácter irrepartible o repartible que establezcan los estatutos o, en su defecto, la asamblea general; $y$, en su caso, participación de las personas trabajadoras asalariadas en los resultados de la cooperativa, sin perjuicio de su tratamiento contable como gasto.

3.- En tanto que el Fondo de Reserva Obligatorio no alcance un importe igual al cincuenta por ciento del capital social, la dotación mínima establecida en favor de la contribución para la educación y promoción cooperativa y otros fines de interés público podrá reducirse a la mitad. (...)»

\section{"Artículo 72.-Contribución para la educación y promoción cooperativa y otros fines de interés público.}

1.- La contribución obligatoria impuesta sobre los excedentes citada en el artículo 70.2.a) se destinará, en aplicación de las líneas básicas fijadas por los estatutos o la asamblea general, a alguna de las siguientes finalidades de interés público:

a) La formación y educación de sus personas socias y personas trabajadoras sobre el cooperativismo, actividades cooperativas y otras materias no relacionadas con el puesto de trabajo.

b) La promoción de las relaciones intercooperativas, incluyendo la cobertura de gastos por la participación en entidades creadas para la promoción, asistencia, dirección común o actividades de apoyo entre cooperativas. 
c) La promoción educativa, cultural, profesional y asistencial, así como la difusión de las características del cooperativismo en el entorno social en que se desenvuelva la cooperativa y en la sociedad en general.

d) La promoción del uso del euskera.

e) La promoción de nuevas empresas cooperativas mediante aportaciones dinerarias a una entidad sin ánimo de lucro promovida por el movimiento cooperativo vasco.

f) La formación y educación de las personas socias y trabajadoras para el fomento en las sociedades cooperativas de una política efectiva para avanzar hacia la igualdad de mujeres y hombres.

2.-El destino de esta contribución obligatoria podrá canalizarse, para las finalidades indicadas en el apartado anterior, a través de aportaciones dinerarias a entidades sin ánimo de lucro o a alguna de las entidades de intercooperación citadas en el apartado 1.b anterior.

Esta entrega a entidades intermediarias estará condicionada a su destino a las finalidades de interés público indicadas, a través de actuaciones de la propia entidad intermediaria o de otras personas físicas o jurídicas a las que dicha entidad destine los recursos recibidos.

3.-La cooperativa no tiene poder de disposición sobre esta contribución, más allá de destinarla a las finalidades de interés público indicadas, por lo que es, en consecuencia, inembargable y debe figurar en el pasivo del balance.

4.-A los fines previstos para esta contribución se destinarán las sanciones económicas que imponga la cooperativa a sus personas socias.

5.-El importe de la referida contribución que no se haya destinado a las finalidades de interés público indicadas por la propia cooperativa deberá entregarse, dentro del ejercicio económico siguiente a aquel en el que se aprobó la distribución del excedente, a entidades sin ánimo de lucro para su destino a las finalidades de interés público establecidas para esta contribución.»

\subsection{Regulación en caso de modificación estructural y disolución y liquidación. Arts. 87.1, 88.5, 89.4 cuarto párrafo, 98.2 letra a)}

\section{«Artículo 87.-Fusiones especiales.}

1.- Siempre que no exista precepto legal que lo prohíba expresamente, las sociedades civiles, mercantiles o entidades de cualquier otro tipo podrán fusionarse con cooperativas mediante la absorción de aquellas por estas o constituyendo una nueva sociedad. En el supuesto de fusión por absorción de una cooperativa por una entidad de otro tipo, se aplicará lo regulado en el artículo 89.4 de esta ley respecto de la transformación, en relación con los fondos a que se refiere el mismo.» 
«Artículo 88.-Escisión de la cooperativa.(...)

5.-En aquellos supuestos en los que se segrega el patrimonio y/o las personas socias de la cooperativa en favor de una entidad no cooperativa y, adicionalmente, como consecuencia de la ejecución de la segregación, se transfieren total o parcialmente los fondos a que se refiere el artículo 89.4 de esta ley para la transformación, registrados en el pasivo del balance de la cooperativa, se aplicarán las reglas previstas en dicho artículo.»

\section{Artículo 89.-Transformación de cooperativas.}

4.-(...) cuarto párrafo

«La contribución para la educación y promoción cooperativa y otros fines de interés público tendrá la aplicación estatutariamente prevista y, en su defecto, la establecida en el artículo 98.2.a) para el supuesto de liquidación de la cooperativa.»

Disolución y liquidación. (...) Artículo 98.-Adjudicación del haber social.

«2.- Satisfechas dichas deudas, el resto del haber social se adjudicará por el siguiente orden:

La contribución para la educación y promoción cooperativa y otros fines de interés público se pondrá a disposición del Consejo Superior de Cooperativas de Euskadi.(...)»

\section{I.3. Comentario general}

a) NovedAd Del TEXTO

La exposición de motivos se refería a este y al FRO de la siguiente forma:

«En cuanto a la aplicación de los excedentes respecto al Fondo de Reserva Obligatorio y a la contribución para la educación y promoción cooperativa y otros fines de interés público, se mantiene la regulación introducida en 2008 en relación con la citada contribución, con la novedad de su aplicación para la formación y educación de las personas socias y trabajadoras con el fin de avanzar en la igualdad de mujeres y hombres».

No es la única modificación que se introduce, pero políticamente puede que sea la más relevante. Junto a ella se reescriben dos apartados y sobre todo se generaliza la opción de usar las figuras del 72.2 para su canalización. 
b) SU DOTACIÓN

La ley sólo contempla, expresamente, que el fondo se nutra por dos vías:

- La principal será el porcentaje de los excedentes disponibles que se recoge en el artículo 70.2 a) aunque su cuantía puede oscilar conforme al 70.3. Anualmente debe destinarse un mínimo de un diez por ciento de los excedentes disponibles a la contribución para la educación y promoción cooperativa y otros fines de interés público. Porcentaje que puede reducirse a la mitad mientras el Fondo de Reserva Obligatorio no alcance un importe igual al cincuenta por ciento del capital social.

- Otra, menos habitual, serán las sanciones económicas que imponga la cooperativa a sus socios que se recoge en el artículo 72.4. Las mismas deben destinarse a los fines previstos para esta contribución.

c) SU DESTINO

El destino debe realizarse conforme a las líneas básicas que se pueden establecer en los estatutos o ser fijadas por la asamblea general, de las finalidades de interés público señaladas en el artículo 72.1:

- La formación y educación de sus socios y trabajadores sobre el cooperativismo, actividades cooperativas y otras materias no relacionadas con el puesto de trabajo.

- La promoción de las relaciones intercooperativas, incluyendo la cobertura de gastos por la participación en entidades creadas para la promoción, asistencia, dirección común o actividades de apoyo entre cooperativas.

- La promoción educativa, cultural, profesional y asistencial, así como la difusión de las características del cooperativismo en el entorno social en que se desenvuelva la cooperativa y en la sociedad en general.

- La promoción del uso del euskera.

- La promoción de nuevas empresas cooperativas mediante aportaciones dinerarias a una entidad sin ánimo de lucro promovida por el movimiento cooperativo vasco.

- La formación y educación de los socios y trabajadores para el fomento en las sociedades cooperativas de una política efectiva para avanzar hacia la igualdad de mujeres y hombres. 
d) Formas de CANALIZACIÓN

La aplicación de la «contribución» puede realizarse de dos formas:

- La habitual será la decisión directa de la propia cooperativa, normalmente tomada por el órgano de administración, dentro de las líneas de aplicación que dentro de la ley se hayan establecido en los estatutos o determine la asamblea.

- Adicionalmente, el artículo 72.2 posibilita su entrega a entidades sin ánimo de lucro o a alguna de las entidades intercooperativas que se señalaban como destinatarias en la letra $b$ de su número 1. En este caso, los receptores deberán aplicarlas a alguna de las finalidades de interés público señaladas, a través de actuaciones de la propia entidad intermediaria o de otras personas físicas o jurídicas a las que dicha entidad destine los recursos recibidos. La entrega a las entidades debe ser en aportaciones dinerarias.

\section{e) Plazo para su aplicación}

El 72.5 limita temporalmente el plazo de ejecución directa al establecer que el importe de la referida «contribución» que no se haya destinado, dentro del ejercicio económico siguiente a aquel en el que se aprobó la distribución del excedente, debe entregarse a entidades sin ánimo de lucro para su destino a las finalidades de interés público establecidas para esta contribución.

\section{f) INEMBARGABILIDAD E IRREPARTIBILIDAD}

El 72.3 remarca que la cooperativa no tiene poder de disposición sobre esta contribución, más allá de destinarla a las finalidades de interés público indicadas, por lo que es, en consecuencia, inembargable y debe figurar en el pasivo del balance.

Dado lo anterior tampoco cabe que se reparta directamente entre los socios, al estar afectos a unos fines, sin perjuicio de que puedan ser beneficiarios de su aplicación dentro de los fines establecidos (art. 72.1).

g) Regulación en CASO de MOdificACIÓN ESTRUCtURAL, DISOLUCIÓN O LIQUIDACIÓN

La regulación de los artículos arts. 87.1, 88.5, 89.4 cuarto párrafo y 98.2 letra a) obedece a la señalada irrepartibilidad de la «contribu- 
ción». Los supuestos previstos son de salida del mundo cooperativo existiendo «contribución» aún sin aplicar.

Así:

- Disolución y liquidación. En la adjudicación del haber social, una vez satisfechas las deudas que se indican, el resto del haber social se adjudica poniendo en primer lugar a disposición del Consejo Superior de Cooperativas de Euskadi la contribución para la educación y promoción cooperativa y otros fines de interés público (art. 98.2 letra a). La literal redacción del artículo parece indicar que la «contribución» debe responder de las deudas previamente indicadas siendo así dudosa su inembargabilidad.

- Transformación de cooperativas a no cooperativa. Se da a la contribución para la educación y promoción cooperativa y otros fines de interés público la aplicación estatutariamente prevista y, en su defecto, la establecida en el artículo 98.2.a) para el supuesto de liquidación de la cooperativa, entrega al CSCE (art. 89.4. cuarto párrafo).

- Fusión por absorción de no cooperativa a cooperativa. En el supuesto de fusión por absorción de una cooperativa por una entidad de otro tipo, se aplica lo regulado en el artículo 89.4 (transformación) en relación con contribución para la educación y promoción cooperativa y otros fines de interés público (art. 87.1).

- Segregación de patrimonio y/o socios con transferencia de fondos de los de la contribución para la educación y promoción cooperativa y otros fines de interés público a favor de una no cooperativa. En los supuestos en los que se segrega el patrimonio y/o los socios de la cooperativa en favor de una entidad no cooperativa y, adicionalmente, como consecuencia de la ejecución de la segregación, se transfieren total o parcialmente los fondos a que se refiere el artículo 89.4 de esta ley para la transformación, registrados en el pasivo del balance de la cooperativa, se aplica a los mismos las reglas previstas en dicho artículo (art. 88.5).

\section{Evolución de la legislación vasca}

En el análisis de la regulación del fondo en la legislación vasca nos limitaremos al de su regulación básica, dejando al margen los cambios estructurales y la disolución y liquidación, por entenderlos 
de menor interés de cara a las cuestiones que plantearemos al final del artículo.

II.1. La ley de 1982. Ley 1/1982, de 11 de febrero, sobre «Cooperativas». BOPV núm. 33, de 10 de marzo. Art. 27

a) Novedad DeL TEXTO

La exposición de motivos se refería a la actual «contribución» denominándola Fondo de Educación y Promoción Social y al FRO de la siguiente forma:

«Otra novedad la constituye el incremento de los Fondos Obligatorios, así como el cambio de nomenclatura utilizada al referirnos a los mismos, denominándose respectivamente Fondo de Reserva Obligatorio y Fondo de Educación y Promoción Social, duplicándose la aportación al Fondo de Reserva Obligatorio, al que debe destinarse como mínimo el treinta por ciento de los Excedentes Netos, y configurándose este Fondo como una Cuenta de Resultados cuyo fin es la consolidación y viabilidad de la Cooperativa, siendo esencial su perfecta consolidación en situaciones de crisis estructurales como las que padecemos, adquiriendo carácter de subsidiariedad el Fondo de Educación y promoción Sociales, ya que es preciso para poder dotar dicho Fondo consolidad previamente el Fondo de reserva Obligatorio »

La ley fue la primera del Parlamento vasco en desarrollo de la competencia recogida en el artículo 10.23 del Estatuto de Autonomía.

En momentos de grave crisis económica se reforzó la idea de que primero debe consolidarse el FRO para que se consolide la Cooperativa y logrado esto se pueda empezar a desarrollar el FEPS.

b) SU DOTACIÓN

La ley sólo contempla, expresamente, que el fondo se nutra por dos vías, las mismas de la actual ley de 2019:

- La principal será el porcentaje de los excedentes netos (que se definen en el artículo 26 deducidos los impuestos) que se establece en su artículo 27.1 dedicado a Fondos Obligatorios. Primero debía destinase anualmente, como mínimo, un treinta por ciento de los mismos al Fondo de Reserva Obligatorio, hasta que éste alcanzase un importe igual al cincuenta por 
ciento del Capital Social. Una vez alcanzado dicho importe se debía destinar, al menos un diez por ciento, al Fondo de Educación y Promoción Social y un veinte por ciento al Fondo de Reserva Obligatorio.

- Otra, menos frecuente, eran las multas y demás sanciones que por vía disciplinaria se impusieran por la Cooperativa a sus que se recoge en el artículo 27.3.

c) SU DESTINO

El destino debe realizarse conforme a las líneas básicas fijadas por la asamblea general pero dentro de las finalidades señaladas en el artículo 27.4:

- El fomento de la asistencia técnica, la creación de supraestructuras de apoyo a las Cooperativas y, en general, cuantas actividades puedan enmarcarse en el principio de la Intercooperación.

— La formación y educación de los socios en los principios y técnicas cooperativas, así como la difusión de las características de cooperativismo en el medio social en que se desenvuelva la actividad de la Cooperativa.

- De carácter cultural, profesional o benéfico, con destino a la promoción Social del entorno local o de la comunidad en general.

\section{d) Formas de CANALIZACIÓN}

La cuestión no se abordaba, siendo lo habitual que fuera la cooperativa la que canalizara de forma directa el fondo.

e) Plazo para su APLICACIÓN

La cuestión no se abordaba.

f) INEMBARGABILIDAD E IRREPARTIBILIDAD

El 27.3 remarca que el Fondo de Educación y Promoción Social es inembargable.

Dado lo anterior tampoco cabe que se reparta directamente entre los socios, al estar afectos a unos fines, sin perjuicio de que puedan ser beneficiarios de su aplicación dentro de los fines establecidos (art. 27.4). 
II.2. La ley de 1993. Ley 4/1993, de 24 de junio, de Cooperativas de Euskadi. BOPV núm. 135, de 19 de julio de 1993. BOE núm. 35, de 10 de febrero de 2012. Arts. 67 y 68

a) NovedAd DEL TEXTO

La exposición de motivos se refería al Fondo de Educación y Promoción Social de la ley de 1982 como Fondo de Educación y Promoción Cooperativa de la siguiente forma:

«En cuanto a los fondos obligatorios, se mantiene la dotación global a los mismos en un treinta por ciento de los excedentes positivos, debiéndose mantener una dotación mínima al Fondo de Educación y Promoción Cooperativa desde la constitución de la sociedad (...)

Finalmente, se concretan los criterios básicos sobre posibles destinos del fondo de educación y promoción Cooperativa (...)».

Se establece por tanto la obligación de dotar el fondo desde el inicio, ampliándose la enumeración de destinos del mismo.

b) SU DOTACIÓN

La ley establece tres vías por las que se nutre el fondo:

- La principal será el porcentaje de los excedentes disponibles (que se definen en el artículo 67.1) que se establece en su artículo 67.2 a) y ajustado en el 67.3 dedicado a Fondos Obligatorios. Debe destinarse al Fondo de Reserva Obligatorio y al Fondo de Educación y Promoción Cooperativa una cuantía global del treinta por ciento al menos, desglosándose en un mínimo de un diez por ciento al FEPC y un veinte al FRO (67.2.a). No obstante, hasta que el FRO alcance el cincuenta por ciento del capital social, se posibilita reducir la dotación al FEPC a la mitad. Dado que el total mínimo sigue siendo del 30\% la reducción del FEPC implica el mismo aumento proporcional del FRO (67.3 y 68.4.a). Respetando esos mínimos de destinarán al FEPC el porcentaje de excedentes disponibles que establezcan los estatutos o la Asamblea General (art. 68.4.a).

- Otra, menos frecuente, eran las sanciones económicas que imponga la cooperativa a sus socios (art. 68.4.b).

- Adicionalmente, los rendimientos financieros obtenidos por la materialización, dentro del ejercicio siguiente a aquel en que se 
haya efectuado la dotación, en títulos de deuda Pública de la Comunidad Autónoma del País Vasco (art. 68.5. segundo párrafo). Dichos títulos fueron inexistentes durante la mayor parte de la vigencia de la ley.

\section{c) SU DESTINO}

El destino debe realizarse conforme a las líneas básicas fijadas por los Estatutos o la Asamblea General pero a actividades que cumplan alguna de las finalidades señaladas en el artículo 68.3:

- La formación y educación de sus socios y trabajadores en los principios cooperativos y en sus valores o en materias relacionadas con el trabajo y demás actividades cooperativas.

- La promoción de las relaciones intercooperativas, incluyendo la cobertura de gastos por la participación en cooperativas de segundo grado, cooperativas de integración y demás entidades creadas para la promoción, asistencia, dirección común o actividades de apoyo entre cooperativas.

- La promoción cultural, profesional o asistencial, así como la difusión de las características del cooperativismo en el entorno social en que se desenvuelva la cooperativa y en la sociedad en general.

\section{d) Formas de CANALIZACIÓN}

La cuestión no se abordaba, siendo lo habitual que fuera la cooperativa la que canalizara de forma directa el fondo.

\section{e) Plazo para su aplicación}

La cuestión no se aborda directamente, pero se obliga a materializar el FEPC, dentro del ejercicio siguiente a aquel en que se haya efectuado la dotación, en títulos de Deuda Pública de la Comunidad Autónoma del País Vasco (art. 68.5. segundo párrafo). Parece una fórmula de cubrir el interés social de la CAPV obteniendo un interés, mientras se busca un destino definitivo conforme a los posibles.

f) INEMBARGABILIDAD E IRREPARTIBILIDAD

El 68.5 establece que el Fondo de Educación y Promoción Cooperativo es inembargable y que sus dotaciones deben figurar en el pasivo 
del balance con separación de otras partidas. Igualmente, su segundo párrafo establece que la deuda Pública en que se haya materializado no podrá ser pignorada, ni afectada a préstamos o cuentas de crédito.

Dado lo anterior tampoco cabe que se reparta directamente entre los socios, al estar afectos a unos fines, sin perjuicio de que puedan ser beneficiarios de su aplicación dentro de los fines establecidos (art. 68.3).

II.3. El reglamento de 2005. Decreto 58/2005, de 29 de marzo, por el que se aprueba el reglamento de la Ley de Cooperativas de Euskadi. BOPV núm. 73, de 19 de abril. Art. 14

\section{a) NovedAd DEL TEXTO}

La regulación del FEPC no se ve afectada por la primera reforma de la Ley de Cooperativas realizada por la ley 1/2000, de 29 de junio (BOPV núm. 146, de 1 de agosto) pero si por su reglamento de 2005, que en muchos puntos puede considerarse una segunda reforma de la ley.

La exposición de motivos se refería al Fondo de Educación y Promoción Social de la ley de 1982 como Fondo de Educación y Promoción Cooperativa de la siguiente forma:

«Regula el destino del fondo de educación y promoción cooperativa, a través de otras entidades e incluso a través de sus entidades asociativas.»

\section{b) SU DESTINO}

No se altera el destino, pero se establece la obligación de que el informe de gestión o, en su caso, la memoria de la cooperativa recoja las cantidades que con cargo a dicho fondo se hayan destinado a los fines del mismo, con indicación de la labor realizada y, en su caso, mención de las sociedades o entidades previstas en el párrafo 1 del artículo 14 a las que se remitieron para el cumplimento de sus fines (art. 14.4).

\section{C) FORMAS DE CANALIZACIÓN}

A la existente canalización directa del fondo se añade la posibilidad de colaborar con otras sociedades y entidades, pudiendo aportarse a las mismas total o parcialmente, su dotación, para que las destinen 
a cualquiera de los fines previstos legalmente para el cumplimiento de los fines del Fondo de Educación y Promoción (14.1).

En concreto, se posibilita que el Fondo de Educación y Promoción Cooperativa pueda destinarse a su finalidad a través de cooperativas de segundo o ulterior grado, entidades asociativas de cooperativas o entidades de otro tipo, siempre que se cumplan los siguientes requisitos:

- Que la entrega esté condicionada al destino de las cantidades correspondientes por parte de la entidad colaboradora a finalidades incluidas entre los destinos legalmente previstos para el Fondo de Educación y Promoción Cooperativa.

- Que dichas finalidades pactadas sean coherentes con las finalidades estatutarias de la entidad colaboradora que canaliza los recursos (14.2).

\section{d) Plazo para su aplicación}

La cuestión se aborda directamente al obligarse a aplicar la cantidad que pudiera quedar pendiente en el plazo máximo de dos ejercicios desde que se materializara en los títulos de deuda pública previstos en la Ley (14.3).

II.4. La modificación de 2008 de la ley de 1993. Ley 6/2008, de 25 de junio, de la Sociedad Cooperativa Pequeña de Euskadi. BOPV núm. 127, de 4 de julio de 2008. BOE núm. 212, de 3 de septiembre de 2011. Nuevos arts. 67, 68 y 68 bis introducidos mediante su disposición adicional $4{ }^{a}$

a) Novedad Del teXto

La regulación del FEPC escapa de la siguiente modificación de la ley realizada a través de la Ley $8 / 2006$, de 1 de diciembre, de segunda modificación de la Ley de Cooperativas de Euskadi (BOPV núm. 238, de 15 de diciembre de 2006 y BOE núm. 266 de 4 de noviembre de 2011) pero no así de la de 2008.

La exposición de motivos se refiere a los cambios que introducen en la regulación el Fondo que pasa a llamarse «contribución»:

«La disposición adicional cuarta establece una modificación de la Ley 4/1993, de 24 de junio, de Cooperativas de Euskadi, en el sentido de clarificar la naturaleza de los recursos destinados a finalidades de interés público. Para ello, se han revisado su denominación y 
sus finalidades, subrayando su carácter obligatorio. Además, las modificaciones introducidas incorporan una nueva denominación que se ajusta mejor a su verdadera naturaleza; se han revisado sus finalidades tratando de compaginar la realidad social cooperativa con el carácter de interés público de dichas finalidades, y se han actualizado las características de su gestión a la nueva regulación.»

Se modifican los apartados 2 y 3 del artículo 67, derogándose los 3,4 y 5 del artículo 68 relativos a la regulación de la «contribución» que pasa a ser regulada en el nuevo artículo 68 bis (D.A. 4. ${ }^{a}$ ).

El número tercero de la disposición adicional $4 .^{a}$, con una peculiar técnica legislativa, establece la sustituir del término «Fondo de Educación y Promoción Cooperativa» por "contribución para educación y promoción cooperativa y otros fines de interés público» en el apartado 4 del artículo 85, en los apartados 2 y 3 del artículo 94 y en los apartados 3.a) y 3.b) del artículo 139.

b) SU DOTACIÓN

La ley vuelve a contemplar que la «contribución» se nutre por dos vías:

- La principal será el porcentaje de los excedentes disponibles (que se definen en el artículo 67.1) que se establece en su artículo 67.2 b) y ajustado en el 67.3 dedicado a Fondos Obligatorios. Debe destinarse un mínimo del diez por ciento, como contribución obligatoria para educación y promoción cooperativa y a otros fines de interés público. No obstante, hasta que el FRO alcance el cincuenta por ciento del capital social, se posibilita modificar las cuantías obligatorias reguladas en los apartados 2.a) y 2.b), destinando un veinticinco por ciento al Fondo de Reserva Obligatorio y un cinco por ciento como contribución obligatoria.

- La segunda sigue siendo las sanciones económicas que imponga la cooperativa a sus socios (art. 68.bis. 4).

Desaparecen por tanto los intereses de la deuda pública y se da nueva redacción con idéntico contenido a los artículos.

C) SU DESTINO

El destino debe realizarse conforme a las líneas básicas fijadas por los Estatutos o la Asamblea General, pero a actividades que cumplan alguna de las finalidades de interés público señaladas en el artículo 68.bis 1: 
— La formación y educación de sus socios y trabajadores sobre el cooperativismo, actividades cooperativas y otras materias no relacionadas con el puesto de trabajo.

- La promoción de las relaciones intercooperativas, incluyendo la cobertura de gastos por la participación en entidades creadas para la promoción, asistencia, dirección común o actividades de apoyo entre cooperativas.

- La promoción educativa, cultural, profesional y asistencial, así como la difusión de las características del cooperativismo, en el entorno social en que se desenvuelva la cooperativa y en la sociedad en general, y la promoción del uso del euskera.

- La promoción de nuevas empresas cooperativas mediante aportaciones dinerarias a una entidad sin ánimo de lucro promovida por el movimiento cooperativo vasco.

Por tanto, desaparecen como destino las materias relacionadas con el trabajo, aunque puede dudarse de si sigue cabiendo en «demás actividades cooperativas» y desaparece la mención a cooperativas de segundo grado, cooperativas de integración, sin que pueda por ello afirmarse que estén excluidas ya que siguen cabiendo en la redacción general, máxime en las cooperativas de trabajo asociado y con socios trabajadores. Y aparece la promoción educativa externa a la cooperativa (la interna está en el primer punto), diferenciándola de la cultural y se incorpora la promoción del uso del euskera y la de nuevas empresas cooperativas mediante aportaciones dinerarias a una entidad sin ánimo de lucro promovida por el cooperativismo vasco.

\section{d) Formas de CANALIZACIÓN}

La aplicación de la «contribución» se estable de dos formas, incorporando la previsión del reglamento:

- La habitual será la decisión directa de la propia cooperativa, normalmente tomada por el órgano de administración, dentro de las líneas de aplicación que dentro de la ley se hayan establecido en los estatutos o determine la asamblea.

- Adicionalmente, el artículo 68.bis. 2 posibilita respecto de los tres primeros fines (letras a, b y c del 68 bis 1) su entrega a entidades sin ánimo de lucro o a alguna de las entidades de intercooperación citadas en el apartado 1.b del artículo 68 bis. En este caso, los receptores deberán aplicarlas a alguna de las finalidades de interés público señaladas, a través de actuaciones de la propia entidad intermediaria o de otras personas físicas o jurídicas a las 
que dicha entidad destine los recursos recibidos. La entrega a las entidades debe ser en aportaciones dinerarias.

\section{e) Plazo para su aplicación}

El 68.bis.5 limita temporalmente el plazo de ejecución directa al establecer que el importe de la referida "contribución» que no se haya destinado, dentro del ejercicio económico siguiente a aquel en el que se aprobó la distribución del excedente, debe entregarse a entidades sin ánimo de lucro para su destino a las finalidades de interés público establecidas para esta contribución.

\section{f) INEMBARGABILIDAD E IRREPARTIBILIDAD}

El 68.bis.3 establece que la cooperativa no tiene poder de disposición sobre esta contribución, más allá de destinarla a las finalidades de interés público indicadas, siendo, en consecuencia, inembargable y debiendo figurar en el pasivo del balance.

Desaparece la mención a separada y las relativas a la deuda pública.

Dado lo anterior tampoco cabe que se reparta directamente entre los socios, al estar afectos a unos fines, sin perjuicio de que puedan ser beneficiarios de su aplicación dentro de los fines establecidos (art. 68. bis.1).

\section{Regulación estatal. Ley 27/1999, de 16 de julio, de Cooperativas. BOE núm. 170, de 17 de julio. Arts. 56 y 58.}

a) RECORDATORIO

Creemos conveniente subrayar que, a diferencia de la legislación vasca, la normativa estatal sigue diferenciando resultados cooperativos de extracooperativos y extraordinarios y estableciendo diversas reglas mínimas en la aplicación de los excedente según de cuales se trate.

El Fondo se denominada de Educación y Promoción.

b) SU DOTACIÓN

La ley contempla cuatro vías por las que se nutre el fondo:

- La mínima principal será el 5\% de los excedentes cooperativos o de los resultados que establezcan los Estatutos o fije la Asamblea General contemplados en el artículo 58.1 de la Ley. 
- Otra menos frecuente serán las sanciones económicas que imponga la cooperativa a sus socios (art. 56.4.b).

- Adicionalmente, los rendimientos financieros obtenidos por la materialización, dentro del ejercicio siguiente a aquel en que se haya efectuado la dotación, en cuentas de ahorro, en títulos de la Deuda Pública o títulos de Deuda Pública emitidos por las Comunidades Autónomas (art. 56.6).

- Una cuarta sería la posible aplicación de beneficios extracooperativos y extraordinarios, conforme al artículo 58.3.

c) SU DESTINO

El destino debe realizarse conforme a las líneas básicas fijadas por los Estatutos o la Asamblea General, pero a actividades que cumplan alguna de las finalidades señaladas en el artículo 56. 1:

- La formación y educación de sus socios y trabajadores en los principios y valores cooperativos, o en materias específicas de su actividad societaria o laboral y demás actividades cooperativas.

— La difusión del cooperativismo, así como la promoción de las relaciones intercooperativas.

- La promoción cultural, profesional y asistencial del entorno local o de la comunidad en general, así como la mejora de la calidad de vida y del desarrollo comunitario y las acciones de protección medioambiental.

d) Formas de CANALIZACIÓN

La aplicación del FEP se estable de dos formas:

- La habitual será la decisión directa de la propia cooperativa, normalmente tomada por el órgano de administración, dentro de las líneas de aplicación que dentro de la ley se hayan establecido en los estatutos o determine la asamblea.

- Adicionalmente, el artículo 56.2 posibilita que para el cumplimiento de los fines del fondo se pueda colaborar con otras sociedades y entidades, pudiendo aportar, total o parcialmente, su dotación. Asimismo, tal aportación puede llevarse a cabo a favor de la unión o federación de cooperativas en la que esté asociada para el cumplimiento de las funciones que sean coincidentes con las propias del referido fondo. 
A efectos de dar transparencia a la aplicación se exige que el informe de gestión recoja con detalle las cantidades que con cargo a dicho fondo se hayan destinado a los fines del mismo, con indicación de la labor realizada y, en su caso, mención de las sociedades o entidades a las que se remitieron para el cumplimiento de dichos fines (art. 56.3).

\section{e) Plazo para su aplicación}

La cuestión no se aborda directamente, pero se obliga a materializar el FEP, dentro del ejercicio siguiente a aquel en que se haya efectuado la dotación, en cuentas de ahorro, en títulos de la Deuda Pública o títulos de Deuda Pública emitidos por las Comunidades Autónomas, cuyos rendimientos financieros se aplicarán al mismo fin (art. 56.6).

\section{f) INEMBARGABILIDAD E IRREPARTIBILIDAD}

El 56.5 establece que fondo de educación y promoción es inembargable e irrepartible entre los socios, incluso en el caso de liquidación de la cooperativa, y que sus dotaciones deben figurar en el pasivo del balance con separación de otras partidas.

El artículo es en ese punto de difícil conciliación con el 75.2 a que sólo dispone la entrega del FEP una vez satisfechas íntegramente las deudas sociales.

Nada dice de los activos contrapartida del fondo.

Respecto de la materialización en cuentas de ahorro, en títulos de la Deuda Pública o títulos de Deuda Pública emitidos por las Comunidades Autónomas, se establece que los mismos no podrán ser pignorados ni afectados a préstamos o cuentas de crédito (56.6).

\section{Principios cooperativos que lo sustentan}

El Fondo de Educación y Promoción, en sus diversas denominaciones, es característico de las cooperativas y supone destinar una parte de los excedentes anuales al cumplimiento de unas finalidades concretas, contempladas a nivel mundial en los principios cooperativos quinto, sexto y séptimo de la Alianza Cooperativa Internacional. Redactados como Declaración sobre Identidad Cooperativa, adoptada en el Congreso de Manchester de 1995, aparecen hoy en el Reglamento de la ACl aprobado por su Asamblea General, el 11 de abril de 2013, dentro de su artículo 7: 
«5.` principio: Educación, capacitación e información Las cooperativas ofrecen educación y capacitación a sus miembros, representantes electos, administradores y empleados de manera que puedan contribuir de manera efectiva al desarrollo de sus cooperativas. Ofrecen información al público en general, particularmente a los jóvenes y a los líderes de opinión, acerca de la naturaleza y los beneficios de la cooperación.

6. ${ }^{\circ}$ principio: Cooperación entre cooperativas Las cooperativas sirven a sus miembros con mayor eficacia y fortalecen el movimiento cooperativo trabajando unidas a través de estructuras locales, nacionales, regionales e internacionales.

7. ${ }^{\circ}$ principio: Interés por la comunidad Las cooperativas trabajan en pro del desarrollo sostenible de sus comunidades aplicando politicas adoptadas por sus miembros.»

Ellos son los principios en los que se basa el Fondo y que marcan las finalidades del mismo que con mayor o menor fortuna nos encontramos redactadas en la legislación cooperativa española: estatal y autonómica.

\section{Cuestiones que plantea}

a) DenOMINACIÓN

El Fondo de Educación y Promoción experimenta en ley vasca diversas modificaciones en cuanto a su denominación, cambiando el apellido Social por el Cooperativo, hoy Contribución para la educación y promoción cooperativa y otros fines de interés público desde 2008.

Por un lado, no puedo compartir la necesidad, ni conveniencia de cambiar de nombre a algo comúnmente conocido como tal, sin que personalmente haya detectado en cooperativa alguna motivo para el cambio. Si lo analizamos veremos que el nuevo nombre parece obedecer al carácter temporal de algo generado en la cooperativa pero que debe aplicarse en corto plazo o entregarse. Lo cual tampoco me convence como analizaré en el oportuno punto (destino).

Es un Fondo que se genera por la cooperativa, basado en los principios en los que el modelo se sustenta y que puede aplicase a una batería de fines. Con el cambio no se introdujo ninguno que no estuviera y simplemente se introdujeron algunos en su denominación, pero con un carácter abierto («y otros fines de interés público»).

Por otro, no acabo de ver las ventajas de que cada autonomía llame de forma distinta a lo mismo (sin discutir la competencia para 
que lo haga), ni que pueda ir desvirtuándolo de los principios que la $\mathrm{ACl}$ se encarga de ir actualizando mediante añadidos diversos que no sólo clarifican lo que ya estaba pero que con la redacción que reciben pueden llevar a la confusión de considerar excluidos los similares.

Tampoco desde un punto de vista práctico me convence por ser una denominación interminable que acaba reducida a COFYP, que dice aún menos que la tradicional de Fondo de Educación y Promoción.

b) SU DOTACIÓN

La ley contempla dos vías de dotación, aunque llegó a contemplar tres: un porcentaje sobre los excedentes cooperativos fijado en estatutos o por la Asamblea y que esta puede incrementar salvo fijación estatutaria y las posibles sanciones económicas que la cooperativa interponga a sus socios.

Han desaparecido los intereses que la propia "contribución» pudiera generar. Esta desaparición parece obedecer al escaso plazo que se prevé pueda estar en la cooperativa y tal vez a motivos fiscales.

Si atentemos al panorama cooperativo nacional nos encontramos con que otras regulaciones se refieren a su aplicación a cuentas de ahorro o títulos de deuda pública (pe. Ley estatal 56.5 D. Legislativo valenciano 2/2015). Esos destinos generarán intereses y la lógica del fondo nos debería llevar a su afección al mismo.

Adicionalmente, otras leyes cooperativas incluyen como fuentes las subvenciones, dotaciones y cualquier tipo de ayuda recibida de los socios o de terceros para el cumplimiento de los fines propios del Fondo (p.e legislaciones cooperativas andaluza, navarra y valenciana).

Entiendo por tanto que pueden aumentarse en la ley las vías de dotación, sin perjuicio de que estas puedan producirse al margen de la misma.

\section{c) SU DESTINO}

La redacción tampoco me parece adecuada, prefiriendo personalmente la de la Ley de 1993 en su versión inicial o la de la Ley estatal actual y ello tanto por dejar fuera (o parecer que los deja) aspectos que entiendo comprendidos, como por optar a una enunciación de fines parciales que deberían ser meros ejemplos y que pueden interpretarse como excluyentes de otros que, a mi juicio, deberían estar igualmente amparados. 
La Ley de 1993 en su versión original agrupaba, como la actual estatal, los destinos en tres Grupos. En el 2008, profundizado en el 2019, desaparecen las materias relacionadas con el trabajo, aunque se mantiene la promoción profesional en el entorno social y se empieza a ampliar la lista. Entiendo que las tres últimas de la actual ley tiene encaje en las tres primeras, resultando reiterativas.

No puedo compartir la técnica enunciativa, que puede ser clarificadora pero que a mi juicio, de no indicarse que no es limitativa, puede servir por ejemplo para discutir que planes de igualdad racial no estén contemplados o que la educación en otros idiomas no quepa como destino de la «contribución» cuando parecen caber sin duda dentro de la enunciación $\mathrm{ACl}$. Igualmente, la eliminación de las materias relacionadas con el trabajo, de no reinterpretarse incorporada en otro punto, puede chocar con el $5 .^{\circ}$ Principio que habla de capacitación y con la tradición cooperativa del fondo que lo sustenta.

Igualmente, me genera dudas que los gastos de estructura intercooperativa (cooperativas de segunda grado o Grupos) puedan Ilegar a absorber la totalidad del Fondo mediante el simple desplazamiento de socios trabajadores de las cooperativas miembro a las de estructura.

\section{d) Formas de CANALIZACIÓN}

La aplicación del FEP se estable de dos formas: la directa por la cooperativa y la indirecta, mediante la entrega de aportaciones dinerarias a un tercero.

El sistema plantea varias cuestiones:

- A la vista de que los excedentes cooperativos varían año a año y pueden ser muy distintos, ¿por qué no se permite que la cooperativa retenga la "contribución» a fin de garantizar unos ingresos recurrentes a las organizaciones beneficiarias?

En la práctica me he encontrado con cooperativas con problemas para buscar beneficiarios en años especialmente buenos y con cooperativas que han tenido que denegar apoyo a terceros que eran beneficiarios en años malos.

Considero que si lo que pretende es que la «contribución» se use, se mueva, hay formas de control que permitan que la cooperativa administre su «contribución» a fin de que los programas beneficiarios puedan garantizarse temporalmente.

Cada vez más es importante no sólo lo que se recibe, sino que la cantidad sea recurrente estando garantizada durante un plazo. 
No se trataría tanto de que efectivamente lo usen como de que dispongan de un plan sobre su aplicación. Por ejemplo, entregar la cantidad en cinco anualidades de forma que se financie la totalidad de un proyecto reteniendo, todo o parte, a fin de garantizar el control de su correcta ejecución.

- ¿Por qué se permite la entrega a un tercero para que lo destine sin exigir plazo y no se permite crear algo similar en la propia cooperativa sin necesidad de recurrir a una nueva persona jurídica externa? Piénsese en algo similar a lo que podría ser el régimen de secciones aplicado a este fin. Un patrimonio afecto al fin, administrado por la propia cooperativa.

Debe considerarse que si la o las cooperativas generan suficientes fondos pueden crear una estructura intercooperativa para el desarrollo del fin o hasta por ejemplo una fundación ¿por qué imposibilitar a las pequeñas hacer lo que pueden hacer las grandes o por qué obligar a crear una fundación o asociación independiente?

- Si la entidad a la que se entrega la «contribución» cumple estatutariamente los fines y se obliga a ello ¿Cuál es la responsabilidad de la cooperativa en caso de que la entidad intermedia no lo destine finalmente a uno de los fines previstos en la ley 27/1999? Y ello tanto ante la Administración como frente a la entidad intermedia y en cuanto a legitimaciones y procedimientos.

Por último, creo altamente recomendable por transparencia, por control y por concienciación a los socios de que mantenga la obligatoriedad de incluir en el informe de gestión, con detalle, las cantidades que con cargo a dicho fondo se hayan destinado a los fines del mismo, con indicación de la labor realizada y, en su caso, mención de las sociedades o entidades a las que se remitieron para el cumplimiento de dichos fines en términos similares a los exigido por la Ley estatal, andaluza o riojana y hoy previstos en el Reglamento de 2005.

\section{e) Plazo para su aplicación}

Aun entendiendo que la limitación temporal es para garantizar que realmente se use en alguno de los destinos previsto, no puedo compartirla.

Creo que le exigencia debería centrarse en la existencia de un plan de gasto aprobado por el órgano de administración de la cooperativa en un plazo más amplio que el señalado por la ley. Un 
plan que permita asegurar que la financiación del mismo no esta sujeta a ciclos económicos y que no deba abandonarse cuando haya pérdidas. Un plan que podría controlarse y que podría ser objeto de revisión.

Se trataría de pasar de la obligación de usar por haber obtenido excedentes a obligar tener un plan de actuación a desarrollar con garantías de ejecución, aunque haya pérdidas.

Por último, desde un punto de vista práctico debo decir que no he conocido desde 2008, año en que está en vigor el actual sistema, ninguna actuación de control sobre el uso del fondo, ni en plazo, ni en contenido.

\section{f) INEMBARGABILIDAD E IRREPARTIBILIDAD}

Con la actual redacción parece que la «contribución» responde ante las deudas sociales dada la redacción del artículo 98.2 a), no quedando tampoco claramente al margen en procesos concursales.

El problema no se resuelve porque sus dotaciones figuren en el pasivo del balance con separación de otras partidas. Lo embargable no es el pasivo sino el activo en el que aquel recae. Si añadimos que en muchos casos son aportaciones dinerarias no separadas que otras serán de imposible individualización.

La parte positiva es la poca incidencia práctica que suelen tener, máxime si deben usarse en un periodo tan corto como para evitar que se puedan ir acumulando durante años.

Desde un punto de vista teórico creemos que la regulación de la inembargabilidad debe perfeccionarse. Máxime si quisiera desarrollarse un sistema que permita encauzar el fondo a proyectos a medio y largo plazo.

En otras normas autonómicas (p.e. Madrid o Valencia) se prevé su posible materialización en bienes de inmovilizado y una mención en el Registro de la Propiedad en el que se halle inscrito, a su carácter inembargable. Esta lógica solución puede no ser adecuada en casos como los de la afección de una sala de reuniones de la empresa a formación, en la que la inscripción de ese posible derecho podría hacer inconstituible una hipoteca por las dificultades prácticas en su realización.

Por último, resultaría lógica la salvedad presente en la legislación madrileña de que el fondo debe responder por las deudas contraídas en la ejecución de sus fines. Si se contrata una formación con cargo al fondo y no se paga este debería responder. En la práctica se de- 
mandará a la cooperativa por todos sus bienes, pero la cuestión es no hallar argumento jurídico para defender en ese caso la inembargabilidad del fondo.

\section{g) DeCisión sobre porcentaje dotado:}

Con la ley de 1982 era habitual que las cooperativas estableciesen, a la hora de distribuir los excedentes, en la Asamblea General Ordinaria el porcentaje que dotarían al Fondo de Educación y Promoción. Pese a la posibilidad legal de incrementarlo, lo habitual era su dotación mínima. Aunque fuera algo mecánico, la Asamblea dotaba el Fondo y recordaba así su existencia.

Por normativa contable la dotación del fondo, que se convirtió en gasto, pasó a realizarse al cierre de cuentas anuales, incorporándose en las que aprueban muchas Asambleas Generales Ordinarias y ya no tanto como decisión de distribución de excedentes. Dado que las cuentas están cerradas, son gasto y afectan al propio impuesto de sociedades también calculado, nos encontramos que difícilmente la Asamblea va a plantearse incrementar la dotación mínima ya que ese incremento implicaría probablemente reformular las cuentas.

Hoy en día nos encontramos cooperativas que deciden el porcentaje en Asamblea (el que ya esta en las cuentas, lo aprueban), otras en las que se informa del porcentaje y otras que se aprueban las cuentas en general estando el fondo deducido como gasto en las mismas.

Sin perjuicio de su carácter de gasto, sigo creyendo en la conveniencia didáctica de que los socios sepan que el Fondo existe, que lo doten y conozcan en que se gasta, para que sirve. Que conozcan lo que a través del mismo se aporta a la cooperativa o a la sociedad en la que se desarrolla y que se les recuerde que la dotación mínima es un mínimo que la Asamblea debe tener la posibilidad real de incrementar. Todo ello puede seguir haciéndose, pero que con la actual redacción también puede y suele evitarse.

\section{Bibliografía}

CAMPUZANO, A.B., ENCISO, M. y MOLINA, C. (Coord). 2019. «Sociedades Cooperativas», Memento práctico 2020-2021, Ed. Francis Lefebvre. Págs. 214-216.

GADEA, E., BUITRON, P. y NAGORE, I. 1999. Derecho de las Cooperativas. Universidad de Deusto. Bilbao. 2 ediciones. Págs. 222-224. 
MERINO, S. (Dir). 2008. Manual de Derecho de Sociedades Cooperativas, Consejo Superior de Cooperativas de Euskadi y Universidad del País Vasco, Vitoria-Gasteiz. Págs. 187-190.

NAGORE, I. 1998. "Análisis de la evolución legislativa española en materia cooperativa entre 1942 y 1993». Boletín de la Asociación Internacional de Derecho Cooperativo. Número 32, I 99. 130 págs. Facultad de Derecho. Universidad de Deusto.

PAZ, N. (Dir.). 1999. "Glosa a la Ley de Cooperativas de Euskadi». Consejo Superior de Cooperativas de Euskadi, Vitoria-Gasteiz, Págs. 255-263. 


\section{Derechos de autor}

El Boletín de la Asociación Internacional de Derecho Cooperativo es una revista de acceso abierto lo que significa que es de libre acceso en su integridad inmediatamente después de la publicación de cada número. Se permite su lectura, la búsqueda, descarga, distribución y reutilización legal en cualquier tipo de soporte sólo para fines no comerciales y según lo previsto por la ley; sin la previa autorización de la Editorial (Universidad de Deusto) o el autor, siempre que la obra original sea debidamente citada (número, año, páginas y DOI si procede) y cualquier cambio en el original esté claramente indicado.

\section{Copyright}

The International Association of Cooperative Law Journal is an Open Access journal which means that it is free for full and immediate access, reading, search, download, distribution, and lawful reuse in any medium only for non-commercial purposes, without prior permission from the Publisher or the author; provided the original work is properly cited and any changes to the original are clearly indicated. 